\title{
PENGARUH KETIDAKSEIMBANGAN BEBAN TERHADAP STABILITAS STEADY STATE
}

\author{
Asmar \\ Teknik Elektro, Universitas Bangka Belitung \\ asmarubb2@gmail.com
}

\begin{abstract}
The stability of the electric power system is related to the balance of power in the system. When a power change occurs, the rotor will swing affecting the power angle, rotation speed, frequency and stability of the system. The Unbalanced load causes the momentary power of the generator to contain the sinusiodal component. To know the effect of sinusiodal component, must be known relation between power angle with momentary power. The relationship is determined by the symmetric component method. The power angle relationship with the momentary power obtained is applied to the swing equation. With the linearization of the equation, it can be seen the effect on steady state generator stability. The results showed that an increase in load imbalance caused a decrease in the stability limit.
\end{abstract}

Keywords: Unbalanced load, symmetrical component,instantaneous power, steady state stability

\section{INTISARI}

Stabilitas sistem tenaga listrik berhubungan dengan keseimbangan daya dalam sistem. Ketika terjadi perubahan daya, rotor akan berayun sehingga mempengaruhi sudut daya, kecepatan putaran, frekuensi dan stabilitas sistem. Ketidakseimbangan beban menyebabkan daya sesaat generator mengandung komponen sinusiodal. Untuk mengetahui pengaruh komponen sinusiodal, harus diketahui hubungan antara sudut daya dengan daya sesaat. Hubungan tersebut ditentukan dengan metode komponen simetris. Hubungan sudut daya dengan daya sesaat yang diperoleh diterapkan pada persamaan ayunan. Dengan linerisasi persamaan tersebut, dapat diketahui pengaruhnya terhadap stabilitas steady state generator. Hasil penelitian menunjukkan bahwa peningkatan ketidakseimbangan beban menyebabkan penurunan batas stabilitas.

Kata kunci : ketidakseimbangan beban, komponen simetris, daya sesaat, stabilitas steady state

\section{PENDAHULUAN}

Tegangan tiga fasa yang ideal adalah tegangan yang seimbang. Tetapi dala pengoperasian sistem tenaga listrik, tegangan pada jaringan umunya dalam kondisi yang tidak seimbang. Penyebab ketidakseimbangan ini adalah adalah pembagian beban yang berbeda antara satu fasa dengan fasa lainnya pada sistem tiga fasa [1]. Penyebab lainnya adalah hubungan belitan trafo [2] dan saluran yang tidak ditransposisikan [3]. Ketidakseimbangan dapat merambat dari satu bagian kebagian lainnya sehingga pada bagian tertentu dari jaringan ketidakseimbangan akan semakin besar [4,5].

Pada kondisi seimbang, daya sesaat memiliki nilai yang tetap [6], sedangkan pada kondisi takseimbang, daya sesaat tiga fasa mengandung dua komponen, yaitu komponen yang nilainya tetap dan komponen yang berosilasi dengan frekuensi dua kali frekuensi sumber [7,8]. Komponen daya aktif merupakan daya aktif tiga fasa dan nilainya dipengaruhi oleh arus urutan positif sedangkan komponen sinusiodal dipengaruhi oleh arus urutan negatif [9]. Pada kondisi tak seimbang, arus urutan negatif menghasilkan mmf (magnetomotive force) yang berputar berlawanan dengan putaran rotor, sedangkan resultan $m m f$ oleh arus urutan nol adalah nol [10]. Hubungan antara daya sesaat dengan sudut dapat diperoleh dengan metode komponen simetris [11].

Salah satu aspek penting dalam pengoperasian sistem tenaga adalah stabilitas. Stabilitas berhubungan dengan keseimbangan daya pada sistem. Untuk menjaga keseimbangan daya, perubahan daya pada jaringan harus diikuti oleh perubahan daya pada generator. Stabilitas diklasifikasikan menjadi stabilitas steady state, stabilitas transient dan stabilitas dinamis. Stabilitas steady state adalah kemampuan sistem tenaga untuk tetap mempertahankan keserempakannya akibat perubahan atau 
gangguan kecil yang terjadi pada sistem tersebut, misalnya perubahan beban secara perlahan, tanpa melibatkan pengaruh sistem penguatan dan governor $[6,12]$. Redaman dan frekuensi teredam dapat dianalisis berdasarkan nilai eigen dari persamaan linear ayunan sudut daya $[6,10,13]$. Penelitian ini membahas tentang pengaruh ketidakseimbangan beban terhadap stabilitas steady state.

\section{il. Metode Penelitian}

Metode penelitian yang digunakan adalah dengan menganalisis daya sesaat akibat ketidakseimbangan [11]. Daya sesaat tersebut disubstitusi kepersamaan ayunan sudut daya. Kemudian persamaan tersebut dilinearisasi sehingga diperoleh model linear ayunan sudut daya. Dengan analisis nilai eigen, diperoleh redaman, frekuensi ayunan sudut daya dan batas stabilitas akibat ketidakseimbangan.

\section{A. Daya Generator Pada Beban Tidak Seimbang}

Daya generator pada gambar 1 dapat dianalisis dengan metode komponen simetris. Daya pembangkitan generator pada kondisi beban tidak seimbang adalah [11] :

$$
\begin{gathered}
p_{e}=P_{1}+p_{2} \\
P_{1}=\frac{3|E|}{\left|Z_{1}\right|}\left(\frac{R_{1}}{\left|Z_{1}\right|}|E|+\left|V_{a 1}\right| \cos \left(\delta+\beta_{1}-\phi_{1}\right)\right) \\
p_{2}=\frac{3|E| V_{a 2} \mid}{\left|Z_{2}\right|} \cos \left(-2 \omega_{s} t-\left(\delta+\beta_{1}\right)-\phi_{2}\right) \\
\phi_{1}=\tan ^{=1}\left(\frac{X_{1}}{-R_{1}}\right)+\beta_{1} \\
\phi_{2}=\tan ^{=1}\left(\frac{X_{2}}{-R_{2}}\right)+\beta_{2}
\end{gathered}
$$

dengan :

$P_{1}:$ daya aktif generator

$p_{2}:$ osilasi daya generator

$\left|V_{a 1}\right|$ : nilai rms tegangan urutan positif bus 1

$\left|V_{a 2}\right|$ : nilai rms tegangan urutan negatif bus 1

$Z_{1}$ : impedansi urutan positif

$Z_{2}$ : impedansi urutan negatif

$\delta$ : sudut daya

$\beta_{1}$ : sudut tegangan urutan positif bus 1

$\beta_{2}$ : sudut tegangan urutan negatif bus 1 .

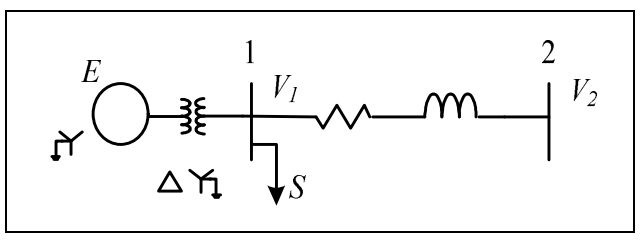

Gambar 1. Jaringan yang digunakan untuk studi kasus

\section{B. Persamaan Ayunan Sudut Daya}

Persamaan ayunan sudut daya adalah $[6,10,12]$ :

$$
\begin{aligned}
& \frac{H}{\pi f_{0}} \frac{d^{2} \delta}{d t^{2}}=P_{m}-p_{e} \\
& \frac{H}{\pi f_{0}} \frac{d^{2} \delta}{d t^{2}}=P_{m}-P_{1}-p_{2}
\end{aligned}
$$

dengan :

$H$ : Konstanta kelembaman generator

$\delta$ : Sudut daya

$P_{m} \quad$ : daya mekanik

Pada analisis stabilitas steady state, daya sesaat generator pada persamaan (1) dihitung berdasarkan tegangan transient generator dan reaktansi transient.

\section{Model Linear Ayunan Sudut Daya}

Dengan linearisasi persamaan (6) diperoleh persamaan differensial linear ayunan sudut daya, yaitu

$$
\begin{gathered}
\left(s^{2}+\left(\frac{\omega_{s} D}{2 H}\right) s+\frac{\omega_{s}}{2 H}\left(K_{1}+\left(\frac{K_{2} s}{s^{2}+4 \omega_{s}^{2}}-\frac{2 K_{3} \omega_{s}}{s^{2}+4 \omega_{s}^{2}}\right)\right)\right) \Delta \delta_{0}^{\prime}(s)=\frac{\omega_{s}}{2 h} \\
K_{1}=\frac{-3\left|E^{\prime}\right|\left|V_{a 1}\right|}{\left|Z_{1}\right|} \sin \left(\delta_{0}^{\prime}+\beta_{1}-\phi_{1}^{\prime}\right) \\
K_{2}=\frac{3\left|E^{\prime}\right| V_{a 2} \mid}{\left|Z_{2}\right|} \sin \left(-\left(\delta_{0}^{\prime}+\beta_{1}\right)-\phi_{2}\right) \\
K_{3}=\frac{3\left|E^{\prime}\right| V_{a 2} \mid}{\left|Z_{2}\right|} \cos \left(-\left(\delta_{0}^{\prime}+\beta_{1}\right)-\phi_{2}\right)
\end{gathered}
$$

dengan :

$\Delta \delta_{0}{ }^{\prime}$ : ayunan sudut daya

$\delta_{0}{ }^{\prime}$ : sudut daya awal

Persamaan karakteristik ayunan sudut daya adalah :

$s^{4}+\left(\frac{\omega_{s} D}{2 H}\right) s^{3}+\left(4 \omega_{s}^{2}+\frac{K_{1} \omega_{s}}{2 H}\right) s^{2}+\left(\frac{2 D \omega_{s}^{3}}{H}+\frac{K_{2} \omega_{s}}{2 H}\right) s+\frac{2 K_{1} \omega_{s}^{3}}{H}-\frac{K_{3} \omega_{s}^{2}}{H} \quad(11$ 
Gambar 2 menunjukkan diagram blok ayunan sudut daya. Terdapat komponen sinusiodal yang mempengaruhi ayunan sudut daya. Bagian input terdiri dari selisih daya mekanik dengan daya aktif generator dan osilasi daya generator. Tanggapan sudut daya adalah jumlah tanggapan terhadap kedua input tersebut.

Ayunan sudut daya berdasarkan sudut daya keadaan steady state adalah [14]:

$$
\delta=\delta_{0}^{\prime}+\Delta \delta_{0}^{\prime}+\gamma
$$

dengan :

$\gamma$ : pergeseran fasa antara sudut daya transient dan sudut daya keadaan steady state

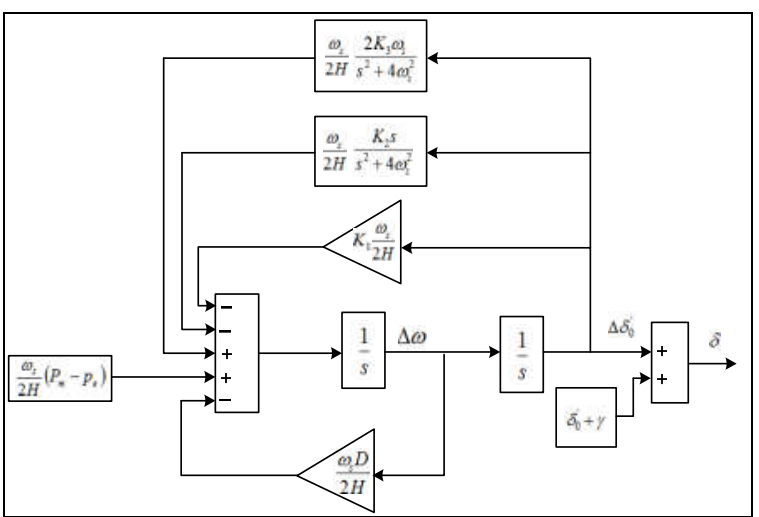

Gambar 2. Diagram blok model linear ayunan sudut daya pada kondisi beban tidak seimbang

\section{Batas Stabilitas}

Batas stabilitas dianalisis berdasarkan kurva daya steady state [14]. Dari model yang dihasilkan pada gambar 2, batas stabilitas ditentukan oleh koofisien $K_{1}, K_{2}$ dan $K_{3}$. Koofisien-koofisien tersebut dihitung berdasarkan reaktans sinkron $\left(X_{S}\right)$ dan tegangan internal genartor $(E)$. Ayunan sudut daya stabil jika koofisien-koofisien tersebut menyebabkan sudut daya yang diumpanbalikkan ke bagian input semakin kecil (mengalami redaman). Bagian real nilai eigen harus bernilai negatif. Generator beroperasi pada daerah stabil jika :

$$
\delta<\delta_{1 k}
$$

$$
\delta_{1 k}=-\tan ^{=1}\left(\frac{X_{2}}{-R_{2}}\right)-\tan ^{-1}\left(\frac{-D}{-4 H}\right)-\left(\beta_{1}-\beta_{2}\right)
$$

Daerah ketidakstabilan dapat dibagi menjadi dua, yaitu daerah 1 dengan penguatan yang kecil dan daerah 2 dengan penguatan yang besar. Daerah dengan penguatan kecil adalah :

$$
\delta_{1 k}<\delta<\delta_{2 k}
$$

$$
\delta_{2 k}=\tan ^{=1}\left(\frac{X_{1}}{-R_{1}}\right)
$$

Daerah dengan penguatan yang besar adalah :

$$
\delta>\delta_{2 k}
$$

\section{E. Studi Kasus}

Hasil yang diperoleh diterapkan pada jaringan yang ditunjukkan pada gambar 1 . Data jaringan dan generator adalah sebagai berikut :

Generator :

$$
\begin{aligned}
& X_{d}=1,81 \mathrm{pu}, X_{d}{ }^{\prime}=0,3 \mathrm{pu}, X_{2}=0,25 \mathrm{pu}, X_{0}=0,04 \\
& \mathrm{pu} \\
& R_{a}=0,003, R_{2}=0,063, R_{0}=0,005 \\
& \text { Konstanta kelembaman }(H)=1 \\
& \text { Faktor redaman }(D)=0.1 \\
& \text { Jumlah kutub }\left(P_{f}\right)=2 \\
& \text { Tranformator }(\mathrm{D} 1-\mathrm{Y}) \\
& \mathrm{Z}_{l}=\mathrm{Z}_{2}=\mathrm{Z}_{0}=0,05+\mathrm{j} 0.15 \mathrm{pu} \\
& \text { Saluran } \\
& \mathrm{Z}_{1}=\mathrm{Z}_{2}=0,1+\mathrm{j} 0,3 \mathrm{pu}, \mathrm{Z}_{0}=0,1+\mathrm{j} 0,9 \mathrm{pu} \\
& \text { Tegangan bus } 2=1 \angle 30 \mathrm{pu}
\end{aligned}
$$

Saluran

Ketidakseimbangan diperoleh dengan mengubah beban pada setiap fasa dari beban lokal. Pengubahan tersebut dilakukan dengan menjaga agar daya nominal tiga fasa tetap sama. Beban yang digunakan pada perhitungan dinyatakan dengan impedansi. Daya nominal beban pada setiap fasa ditunjukkan pada tabel 1 .

TABEL 1

PEMBAGIAN BEBAN PADA SETIAP FASA

\begin{tabular}{|c|c|c|c|}
\hline \multirow{2}{*}{ No. } & \multicolumn{3}{|c|}{ Daya nominal beban $(\mathrm{pu})$} \\
\cline { 2 - 4 } & Fasa a & Fasa b & Fasa c \\
\hline 1 & $0,3+\mathrm{j} 0,1$ & $0,3+\mathrm{j} 0,1$ & $0,3+\mathrm{j} 0,1$ \\
\hline 2 & $\begin{array}{c}(0,3+\mathrm{j} 0,1)- \\
20 \%\end{array}$ & $\begin{array}{c}(0,3+\mathrm{j} 0,1)+ \\
20 \%\end{array}$ & $0,3+\mathrm{j} 0,1$ \\
\hline 3 & $\begin{array}{c}(0,3+\mathrm{j} 0,1)- \\
40 \%\end{array}$ & $\begin{array}{c}(0,3+\mathrm{j} 0,1)+ \\
40 \%\end{array}$ & $0,3+\mathrm{j} 0,1$ \\
\hline
\end{tabular}




\begin{tabular}{|c|c|c|c|}
\hline 4 & $\begin{array}{c}(0,3+\mathrm{j} 0,1)- \\
60 \%\end{array}$ & $\begin{array}{c}(0,3+\mathrm{j} 0,1)+ \\
60 \%\end{array}$ & $0,3+\mathrm{j} 0,1$ \\
\hline 5 & $\begin{array}{c}(0,3+\mathrm{j} 0,1)- \\
80 \%\end{array}$ & $\begin{array}{c}(0,3+\mathrm{j} 0,1)+ \\
80 \%\end{array}$ & $0,3+\mathrm{j} 0,1$ \\
\hline 6 & $\begin{array}{c}(0,3+\mathrm{j} 0,1)- \\
100 \%\end{array}$ & $\begin{array}{c}(0,3+\mathrm{j} 0,1)+ \\
100 \%\end{array}$ & $0,3+\mathrm{j} 0,1$ \\
\hline 7 & $\begin{array}{c}(0,3+\mathrm{j} 0,1)- \\
20 \%\end{array}$ & $(0,3+\mathrm{j} 0,1)-20 \%$ & $(0,3+\mathrm{j} 0,1)+40 \%$ \\
\hline 8 & $\begin{array}{c}(0,3+\mathrm{j} 0,1)- \\
40 \%\end{array}$ & $(0,3+\mathrm{j} 0,1)-40 \%$ & $(0,3+\mathrm{j} 0,1)+80 \%$ \\
\hline 9 & $\begin{array}{c}(0,3+\mathrm{j} 0,1)- \\
60 \%\end{array}$ & $(0,3+\mathrm{j} 0,1)-60 \%$ & $(0,3+\mathrm{j} 0,1)+120 \%$ \\
\hline 10 & $\begin{array}{c}(0,3+\mathrm{j} 0,1)- \\
80 \%\end{array}$ & $(0,3+\mathrm{j} 0,1)-80 \%$ & $(0,3+\mathrm{j} 0,1)+160 \%$ \\
\hline 11 & $\begin{array}{c}(0,3+\mathrm{j} 0,1)- \\
100 \%\end{array}$ & $\begin{array}{c}(0,3+\mathrm{j} 0,1)- \\
100 \%\end{array}$ & $(0,3+\mathrm{j} 0,1)+200 \%$ \\
\hline
\end{tabular}

\section{HASIL DAN PEMBAHASAN}

Gambar 3 menunjukkan penyelesaian nonlinear persamaan (6) dan penyelesaian linear persamaan (7) untuk beban data nomor 5 kemudian daya generator berubah dari 0,1 pu menjadi 0,2 pu. Karena perubahan sudut daya relatif kecil, maka hampir tidak terdapat perbedaan antara penyelesaian linear dan nonlinear. Jadi model yang dihasilkan dapat digunakan untuk analisis stabilitas steady state.

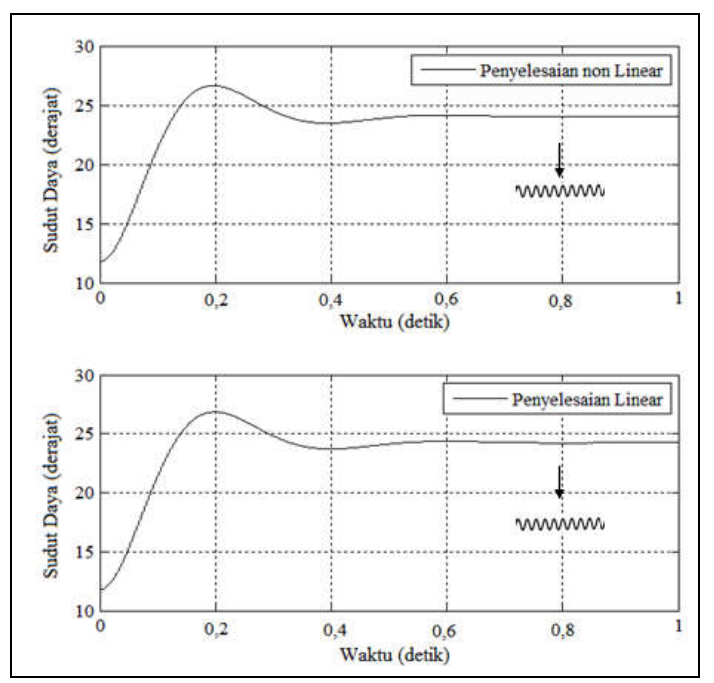

Gambar 3. Penyelesaian nonlinear dan linear ayunan sudut daya

TABEL 2

Hasil Perhitungan Daya dan Sudut Daya Generator

(tegangan generator $1 \angle 10^{\circ} \mathrm{pu}$ )

\begin{tabular}{|l|l|l|l|l|}
\hline No & $\begin{array}{l}\mathrm{P} \\
(\mathrm{pu})\end{array}$ & $\begin{array}{l}\mathrm{Q} \\
(\mathrm{pu})\end{array}$ & $\begin{array}{l}\text { Amp.Osi. Daya } \\
(\mathrm{pu})\end{array}$ & Sudut Daya (derajat) \\
\hline 1 & 0,1065 & 0,0316 & 0,0000 & 12,52 \\
\hline 2 & 0,1064 & 0,0316 & 0,0145 & 12,51 \\
\hline
\end{tabular}

\begin{tabular}{|l|l|l|l|l|}
3 & 0,1063 & 0,0316 & 0,0289 & 12,50 \\
\hline 4 & 0,1060 & 0,0316 & 0,0432 & 12,47 \\
\hline 5 & 0,1057 & 0,0316 & 0,0574 & 12,42 \\
\hline 6 & 0,1052 & 0,0317 & 0,0714 & 12,37 \\
\hline 7 & 0,1063 & 0,0316 & 0,0251 & 12,50 \\
\hline 8 & 0,1059 & 0,0316 & 0,0500 & 12,45 \\
\hline 9 & 0,1051 & 0,0316 & 0,0745 & 12,36 \\
\hline 10 & 0,1041 & 0,0317 & 0,0988 & 12,24 \\
\hline 11 & 0,1027 & 0,0317 & 0,1229 & 12,09 \\
\hline
\end{tabular}

\section{A. Redaman dan frekuensi ayunan sudut daya}

Redaman dan frekuensi ayunan sudut daya diperoleh dengan analisis nilai eigen. Hasil perhitungan nilai eigen ditunjukkan pada tabel 3.

Dari tabel 2, peningkatan ketidakseimbangan beban lebih berpengaruh terhadap osilasi daya generator sehingga bagian real nilai eigen 3 dan 4 juga lebih banyak mengalami perubahan. Semakin besar ketidakseimbangan beban, redaman/penguatan yang disebabkan oleh koofisien $K_{2}$ dan $K_{3}$ juga semakin besar.

TABEL 3

HASIL PERHITUNGAN NILAI EIGEN

\begin{tabular}{|c|c|c|c|}
\hline No & Nilai Eigen 1 dan 2 & Nilai Eigen 3 dan 4 & $\begin{array}{c}\text { Keteranga } \\
n\end{array}$ \\
\hline 1 & $\begin{array}{l}-7,853981 \pm \\
j 16,043694\end{array}$ & - & Stabil \\
\hline 2 & $\begin{array}{l}-7,853979 \pm \\
j 16,043318\end{array}$ & $\begin{array}{l}-0,000002 \pm \\
j 628,318529\end{array}$ & Stabil \\
\hline 3 & $\begin{array}{l}-7,853977 \pm \\
j 16,042059\end{array}$ & $\begin{array}{l}-0,000004 \pm \\
j 628,318527\end{array}$ & Stabil \\
\hline 4 & $\begin{array}{l}-7,853975 \pm \\
j 16,039911\end{array}$ & $\begin{array}{l}-0,000007 \pm \\
j 628,318525\end{array}$ & Stabil \\
\hline 5 & $\begin{array}{l}-7,853972 \pm \\
j 16,036867\end{array}$ & $\begin{array}{l}-0,000008 \pm \\
j 628,318523\end{array}$ & Stabil \\
\hline 6 & $\begin{array}{l}-7,853970 \pm \\
\mathrm{j} 16,032914\end{array}$ & $\begin{array}{l}-0,000011 \pm \\
\mathrm{j} 628,318522\end{array}$ & Stabil \\
\hline 7 & $\begin{array}{l}-7,853984 \pm \\
j 16,042573\end{array}$ & $\begin{array}{c}0,000003 \pm \\
j 628,318526\end{array}$ & $\begin{array}{l}\text { Tidak } \\
\text { Stabil }\end{array}$ \\
\hline 8 & $\begin{array}{l}-7,853987 \pm \\
\mathrm{j} 16,039078\end{array}$ & $\begin{array}{c}0,000006 \pm \\
\mathrm{j} 628,318522\end{array}$ & $\begin{array}{l}\text { Tidak } \\
\text { Stabil }\end{array}$ \\
\hline 9 & $\begin{array}{l}-7,853990 \pm \\
j 16,033453\end{array}$ & $\begin{array}{c}0,000008 \pm \\
j 628,318519\end{array}$ & $\begin{array}{l}\text { Tidak } \\
\text { Stabil }\end{array}$ \\
\hline 10 & $\begin{array}{l}-7,853992 \pm \\
\mathrm{j} 16,025909\end{array}$ & $\begin{array}{c}0,000011 \pm \\
j 628,318515\end{array}$ & $\begin{array}{l}\text { Tidak } \\
\text { Stabil }\end{array}$ \\
\hline 11 & $\begin{array}{l}-7,853995 \pm \\
j 16,016629\end{array}$ & $\begin{array}{c}0,000014 \pm \\
\mathrm{j} 628,318511\end{array}$ & $\begin{array}{l}\text { Tidak } \\
\text { Stabil }\end{array}$ \\
\hline
\end{tabular}

\section{B. Batas stabilitas}

Pada kondisi seimbang, batas stabilitas ditentukan oleh sudut $\phi_{1}$. Karena nilai resistans juga diperhitungkan, batas stabilitas sudut daya pada kondisi seimbang berada pada kuadran kedua bidang kompleks, yaitu 
91,55 $5^{\circ}$. Hasil perhitungan batas stabilitas ditunjukkan pada tabel 4 .

Penurunan batas stabilitas disebabkan oleh $K_{2}$ dan $K_{3}$. Hal ini ditunjukkan pada gambar 4. untuk tegangan nomor 5 pada tabel 4.3. Bagian real nilai eigen 3 dan 4 lebih awal mengalami perubahan tanda dibandingkan nilai eigen 1 dan 2 , yaitu pada sudut $55,22^{\circ}$.

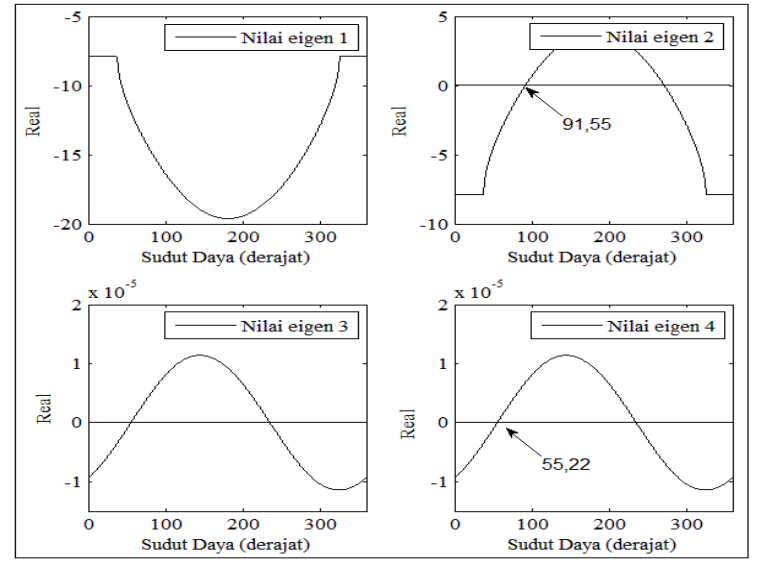

Gambar 4. Pengaruh sudut daya terhadap bagian real nilai eigen untuk data tegangan nomor 5

TABEL 4

KONDISI OPERASI TEGANGAN PADA Bus 1 DAN BATAS STABILITAS

\begin{tabular}{|c|c|c|c|c|c|}
\hline \multirow{3}{*}{ No } & \multicolumn{3}{|c|}{ Tegangan bus 1 } & \multicolumn{2}{c|}{ Batas Stabilitas } \\
\cline { 2 - 6 } & $V_{a}$ & $V_{b}$ & $V_{c}$ & $\begin{array}{c}\text { Sudut } \\
\text { daya } \\
(\text { derajat })\end{array}$ & $\begin{array}{c}\text { Daya } \\
(\mathrm{pu})\end{array}$ \\
\hline
\end{tabular}

\begin{tabular}{|l|l|l|l|l|l|}
\hline 1 & $0,9551 \angle 27,48$ & $0,9551 \angle 27,48$ & $0,9551 \angle 27,48$ & 91,55 & 0,50092 \\
\hline
\end{tabular}

\begin{tabular}{|l|l|l|l|l|l|}
2 & $0,9613 \angle 27,89$ & $0,9500 \angle 27,02$ & $0,9540 \angle 27,54$ & 55,93 & 0,40976 \\
\hline
\end{tabular}

\begin{tabular}{|l|l|l|l|l|l|}
\hline 3 & $0,9675 \angle 28,32$ & $0,9449 \angle 26,57$ & $0,9529 \angle 27,61$ & 55,72 & 0,40869 \\
\hline
\end{tabular}

\begin{tabular}{|l|l|l|l|l|l|l|}
\hline 4 & $0,9736 \angle 28,75$ & $0,9398 \angle 26,13$ & $0,9518 \angle 27,68$ & 55,48 & 0,40746 \\
\hline
\end{tabular}

\begin{tabular}{|l|l|l|l|l|l|}
\hline 5 & $0,9798 \angle 29,19$ & $0,9348 \angle 25,69$ & $0,9506 \angle 27,76$ & 55,22 & 0,40606 \\
\hline
\end{tabular}

\begin{tabular}{|l|l|l|l|l|l|l|}
6 & $0,9859 \angle 29,65$ & $0,9297 \angle 25,27$ & $0,9495 \angle 27,84$ & 54,92 & 0,40449 \\
\hline
\end{tabular}

\begin{tabular}{|l|l|l|l|l|l|l|}
\hline 7 & $0,9591 \angle 28,02$ & $0,9624 \angle 27,84$ & $0,9438 \angle 26,62$ & - & - \\
\hline
\end{tabular}

\begin{tabular}{|l|l|l|l|l|l|l|}
8 & $0,9631 \angle 28,58$ & $0,9696 \angle 28,22$ & $0,9326 \angle 25,80$ & - & - \\
\hline
\end{tabular}

\begin{tabular}{|l|l|l|l|l}
\hline 9 & $0,9671 \angle 29,15$ & $0,9767 \angle 28,62$ & $0,9213 \angle 25,01$ \\
\hline
\end{tabular}

\begin{tabular}{l|l|l|l|l|l|l|}
10 & $0,9710 \angle 29,75$ & $0,9838 \angle 29,04$ & $0,9101 \angle 24,25$ & - & - \\
\hline
\end{tabular}

\begin{tabular}{|l|l|l|l|l|l|}
11 & $0,9750 \angle 30,37$ & $0,9908 \angle 29,47$ & $0,8990 \angle 23,53$ & - & - \\
\hline
\end{tabular}

Untuk kondisi tegangan nomor 7 sampai dengan 11, tidak terdapat daerah operasi yang stabil. Nilai eigen untuk kondisi tegangan nomor 11 diperlihatkan pada gambar 5. Pada gambar tersebut, untuk sudut yang lebih kecil dari $91,55^{\circ}$ bagian real nilai eigen 3 dan 4 bernilai positif (sudut daya mengalami penguatan). Dari hasil perhitungan pada tabel 4, peningkatan ketidakseimbangan beban menyebabkan batas stabilitas semakin kecil.

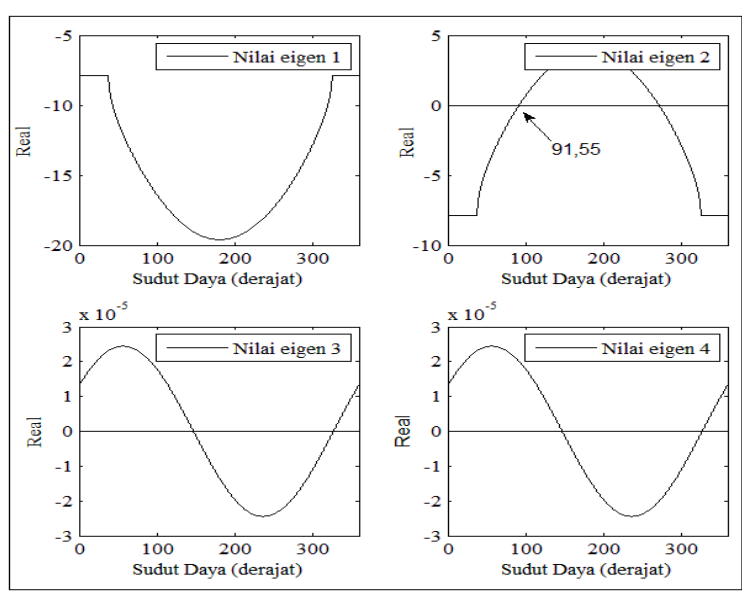

Gambar 5. Pengaruh sudut daya terhadap bagian real nilai eigen untuk data tegangan nomor 11

Karena penurunan batas stabilitas dipengaruhi oleh $K_{2}$ dan $K_{3}$, maka waktu yang dibutuhkan untuk memperkuat ayunan relatif sangat lama. Tetapi hal ini tetap perlu diperhatikan karena pengoperasian sistem tenaga selalu dalam kondisi tidak seimbang. Batas stabilitas ditentukan oleh selisih fasa tegangan urutan positif dengan tegangan urutan negatif. Jadi selisih sudut fasa tersebut perlu dijaga agar tidak menyebabkan sudut daya diperkuat secara terus menerus. Hal ini dapat dilakukan dengan menjaga ketidakseimbangan beban agar berada pada batas-batas tertentu.

Gambar 6 memperlihatkan batas stabilitas kondisi operasi tegangan untuk data nomor 5 .

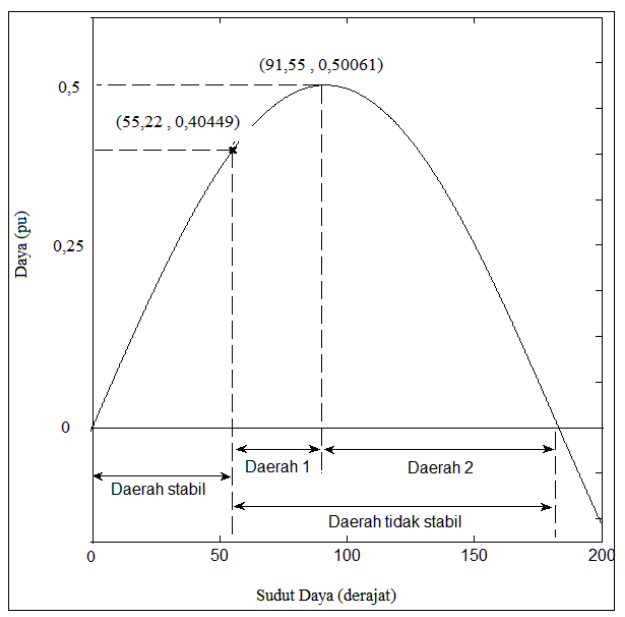

Gambar 6. Kurva daya dan batas stabilitas untuk data tegangan nomor nomor 5 


\section{IV.KESIMPULAN}

Peningkatan ketidakseimbangan beban menyebabkan peningkatan osilasi daya pada generator. Osilasi daya tersebut menyebabkan penurunan batas stabilitas steady state generator.

\section{SARAN}

Penelitian lebih lanjut mengenai metode untuk memperbaiki penurunan batas stabilitas perlu dilakukan misalnya pengaruh kumparan peredam, kelembaman generator, dan Power System Stabilizer (PSS) pada sistem yang tidak seimbang.

\section{Referensi :}

[1] A. von Jouanne dan B. B. Banerjee, "Voltage Unbalance: Power qualityissues, related, standards and mitigation techniques," Electric Power Research Institute, Palo Alto, CA, EPRI Final Rep., May 2000 [2] R. Bergeron, "Voltage Unbalance On Canadian Electrical Association, Montréal, Québec, Project no. 231 D 488, Jan. 1989

[3] M. H. Hesse and J. Sabath, "EHV Double-Circuit Untransposed „Transmission Line-Analysis And Tests, IEEE Trans. Power App. Sys. vol. PAS-90, issue 3, pp. 984-992, May 1971

[4] M. Chindris dkk, "Propagation of Unbalance in Electric Power Systems", Electrical Power Quality and Utilisation, Oktober 2007

[5] P. Paranavithana dkk, "Propagation Of Voltage Unbalance From Hv To. Mv Power Systems" 20th International Conference on Electricity Distribution Prague, 8-11 June 2009

[6] H. Saadat, "Power System Analysis," McGraw-Hill, Singapore, 1999

[7] W.J. Bonwick dan P.J. Hession,'Fast Measurement Of Real And Reactive In Three Phase Citcuits", IEE Proc-A, Vol. 139, Maret 1992

[8] O. Usta dan M. Bayrak “A New Digital Algorithm For Protection Of Synchronous Generators "Against Engineering. System Conference on Power Engineering, Halifax, Canada, Juni 1999

[9] M. Bayrak dan O. Usta, "Instantaneous Power "In Unbalanced' Three Phase System," ELECO'99 International Conference on Electrical and ElectronicaEngineering, 1999

[10] P. Kundur, "Power System Stability And Control", McGraw-Hill, New York, 1994

[11] Asmar dkk, "Kecepatan Putaran Dan Frekuensi Generator Pada Knndici Rehan Tidak Seimbang", Media Elektrika, 2014
[12] W. D. Stevenson, "Analisis sistem tenaga listrik," Erlangga, Jakarta, 1993

[13] R.A. "Gabel dkk,"Sinyal dan sistem linear", Erlangga, 1996

[14] J. Machowski dkk. "Power system dynamics," John Wiley \& Sons,.Ltd,
United Kingdom,2008 